\title{
Research \\ Tissue hemoglobin index: a non-invasive optical measure of total tissue hemoglobin
}

Dean Myers ${ }^{1}$, Michelle McGraw ${ }^{1}$, Mark George ${ }^{2}$, Kristine Mulier ${ }^{2}$ and Greg Beilman²

1BioMeasurement Division, Hutchinson Technology Inc., 40 West Highland Park Drive NE, Hutchinson, MN 55350-9784, USA
2Department of Surgery, University of Minnesota, MMC 11, 420 Delaware St SE, Minneapolis, Minnesota 55455-0390, USA

Corresponding author: Dean Myers, dean.myers@hti.htch.com

Published: 30 November 2009

This article is online at http://ccforum.com/content/13/S5/S2

(c) 2009 BioMed Central Ltd
Critical Care 2009, 13(Suppl 5):S2 (doi:10.1186/cc8000)

\section{Introduction}

The InSpectra ${ }^{\mathrm{TM}} \mathrm{StO}_{2}$ Tissue Oxygenation Monitor, Model 650 (Hutchinson Technology Inc., Hutchinson, MN, USA) provides continuous non-invasive assessment of tissue hemoglobin oxygen saturation $\left(\mathrm{StO}_{2}\right)$ in the clinical setting. Depressed $\mathrm{StO}_{2}$ has been shown to correlate with the severity of systemic hypoperfusion and mortality in traumatic shock patients [1,2] and septic shock patients [3,4]. In addition to $\mathrm{StO}_{2}$, the InSpectra ${ }^{\mathrm{TM}}$ monitor displays the tissue hemoglobin index (THI), a measurement of hemoglobin signal strength useful for determining whether the $\mathrm{StO}_{2}$ sensor is optimally positioned over muscle.

There is growing interest as to whether the THI is clinically useful beyond guiding the placement of a $\mathrm{StO}_{2}$ sensor. More recently the $\mathrm{THI}$ has been studied during the clinical assessment of tissue oxygen perfusion status to convert an $\mathrm{StO}_{2}$ downward slope during arterial occlusion to an index of local oxygen consumption [5] and to assess microvascular reactivity when blood flow is re-established after arterial occlusion [6]. Since invasive blood draws are not always feasible in patients, researchers have sought to establish a link between non-invasive continuous tissue hemoglobin measurements (THCs) and blood total hemoglobin concentration (Hbt) [7-10].

The THI measured over the thenar eminence is potentially comparable with THC in muscle, typically $<1 \mathrm{~g} / \mathrm{dl}$. Since the near-infrared spectroscopy (NIRS) method for measuring the THI assumes a constant but unknown optical path length, the measured tissue volume is unknown. Absolute units are therefore not assignable to the $\mathrm{THI}$ and it is not known whether THI values can be used to compare intermittent nontrended tissue hemoglobin values across a patient population. Also, since the THI signal includes an unknown

$2 \mathrm{D}_{760}=760 \mathrm{~nm}$ second-derivative optical attenuation signal; $\Delta \mathrm{THI}=$ tissue hemoglobin index increase with 3 minutes of venous occlusion; $\mathrm{Hbt}=$ total hemoglobin concentration; NIRS = near-infrared spectroscopy; PSF = probe scaling factor; $\mathrm{StO}_{2}=$ tissue hemoglobin oxygen saturation; $\mathrm{THC}=$ tissue hemoglobin concentration; $\mathrm{THI}=$ tissue hemoglobin index. 
contribution from myoglobin, there is uncertainty whether THI is sensitive to muscle THC and possibly $\mathrm{Hbt}$.

To clarify the physiologic meaning of the THI and to provide InSpectra ${ }^{\mathrm{TM}}$ researchers with insight into whether the $\mathrm{THI}$ has value beyond $\mathrm{StO}_{2}$ sensor placement, a series of in vitro and in vivo experiments was performed. Since no gold standard for muscle hemoglobin concentration exists, we sought to demonstrate that the $\mathrm{THI}$ algorithm is specific and sensitive to $\mathrm{Hbt}$ in isolated blood-tissue phantoms. To evaluate THI variation and to establish a normal reference range for human thenar eminence muscle, the THI was measured in 434 healthy subjects. To estimate the potential contribution of myoglobin and to provide an estimate of the lowest obtainable THI measurement, 30 healthy subjects underwent hand/ forearm blood volume exsanguination with an Esmarch bandage tourniquet procedure. Additionally, the same 30 subjects underwent head-of-bed elevation and pneumatic cuff-induced arterial/venous occlusion to evaluate variable tissue blood volume conditions that could be encountered in a clinical setting and could confound any correlation between the $\mathrm{THI}$ and $\mathrm{Hbt}$. Isovolumetric hemodilution was performed in five pigs to evaluate the potential correlation of the THI to $\mathrm{Hbt}$.

\section{Materials and methods}

Tissue hemoglobin index measurement equipment

The InSpectra ${ }^{\mathrm{TM}} \mathrm{StO}_{2}$ Tissue Oxygenation Monitor emits and detects wavelengths of light at $680 \mathrm{~nm}, 720 \mathrm{~nm}$, $760 \mathrm{~nm}$, and $800 \mathrm{~nm}$ that transcutaneously illuminate and backscatter from human thenar eminence muscle at a maximum depth of $15 \mathrm{~mm}$. Light returned to the monitor is converted into two second-derivative attenuation measurements centered at $720 \mathrm{~nm}$ and $760 \mathrm{~nm}$. The optical hardware and calculations necessary for the second-derivative attenuation and $\mathrm{StO}_{2}$ measurements have been previously described [11].

\section{Tissue hemoglobin index algorithm and calibration}

It has been previously shown that $760 \mathrm{~nm}$ second-derivative attenuation measurements are specific to deoxyhemoglobin optical absorbance [12] and that the blood hemoglobin oxygen saturation $\left(\mathrm{SO}_{2}\right), \mathrm{Hbt}$, and traversed distance of light (optical path length) are three primary physiologic variables that affect the $760 \mathrm{~nm}$ second-derivative optical attenuation signal $\left(2 D_{760}\right)$ [11]. Hbt can therefore be determined for a given magnitude of $\mathrm{SO}_{2}$ and optical path length using $2 \mathrm{D}_{760}$ spectral measurements.

For the present study, the optical path length was not measured. The optical path length for a given wavelength, being grossly dependent upon the optical sensor's distance between the illumination and detection optical fibers, is assumed constant. The THI therefore represents the amount of total hemoglobin within an unknown volume of tissue, and accordingly has arbitrary measurement units. The mean signal depth is estimated to be one-half of the optical sensor spacing, with the maximum signal depth equal to the probe spacing distance (7.5 mm and $15 \mathrm{~mm}$, respectively) [13].

At each possible level of $\mathrm{SO}_{2}$ there is a corresponding linear slope coefficient that empirically describes how $2 D_{760}$ changes with $\mathrm{Hbt}$ at a given hemoglobin oxygen saturation and optical path length. The THI measurement first requires measurement of the $\mathrm{StO}_{2}$, before selecting the linear slope coefficient value $M_{\mathrm{SO}_{2}}$ used to calculate the $\mathrm{THI}$ as follows:

$$
\mathrm{THI}=\frac{M_{\mathrm{SO}_{2}}\left(2 \mathrm{D}_{760}\right)}{\mathrm{PSF}}
$$

The probe scaling factor (PSF) can be used to obtain a common THI scale between different optical probe spacings or optical path lengths. Since all measurements in the present study were obtained with a $15 \mathrm{~mm}$ optical probe spacing, the PSF was set to 1.

A custom-made, isolated, dual-layer blood-tissue phantom apparatus [11] was used to acquire the linear slope coefficient values needed to calibrate the $\mathrm{THI}$ to $\mathrm{Hbt}$ in a tissue phantom. Whole bovine blood containing 10 units $/ \mathrm{ml}$ heparin, and diluted to $10 \mathrm{~g} / \mathrm{dl} \mathrm{Hbt}$ with $0.9 \mathrm{wt} \%$ saline, was pumped through the blood-tissue phantom. The optical sensor was connected to the dual-layer flow cell apparatus. Paired values of $\mathrm{StO}_{2}$ and $2 \mathrm{D}_{760}$ were recorded and saved as the blood $\mathrm{SO}_{2}$ was slowly varied between 0 and $100 \%$. For each paired recording of $\mathrm{StO}_{2}$ and $2 \mathrm{D}_{760}$, a linear slope coefficient value was calculated (Equation (1), PSF = 1, THI arbitrarily set to 10 at $10 \mathrm{~g} / \mathrm{dl} \mathrm{Hbt).} \mathrm{A} \mathrm{nonlinear} \mathrm{curve} \mathrm{fit} \mathrm{of}$ linear slope coefficient versus $\mathrm{StO}_{2}$ was used to produce a calibration look-up table relating the linear slope coefficient to each $\mathrm{StO}_{2}$ level ranging from 0 to $99.9 \%$, in $0.1 \%$ increments. The resultant look-up table was installed within the monitor's software to permanently calibrate $\mathrm{THI}$ to $2 \mathrm{D}_{760}$ for all possible levels of $\mathrm{StO}_{2}$.

\section{Isolated blood-tissue phantom: tissue hemoglobin index sensitivity to total hemoglobin}

To evaluate the robustness of the THI algorithm to $\mathrm{StO}_{2}$ changes at constant $\mathrm{Hbt}$, the dual-layer blood loop apparatus was set up to create low THI, medium $\mathrm{THI}$, and high $\mathrm{THI}$ conditions. Low THI ( 5.8) was created with the flow cell having a $1.0 \mathrm{~mm}$ blood layer thickness and $6 \mathrm{~g} / \mathrm{dl}$ inlet $\mathrm{Hbt}$. To achieve medium THI ( 11.4), the inlet Hbt was increased to $12 \mathrm{~g} / \mathrm{dl}$ at $1.0 \mathrm{~mm}$ blood layer thickness. To obtain high THI ( 18.0), the blood layer thickness was increased from 1.0 to $1.5 \mathrm{~mm}$ at $12 \mathrm{~g} / \mathrm{dl}$ inlet $\mathrm{Hbt}$. At each $\mathrm{THI}$ level, $\mathrm{StO}_{2}$ was adjusted by changing the membrane oxygenator inlet gas concentration from $21 \%$ to $0 \%$ oxygen, with 5\% carbon dioxide and nitrogen for the remaining balance. $\mathrm{StO}_{2}$ and the THI were continuously recorded in order to obtain a linear regression model correlating the $\mathrm{THI}$ to $\mathrm{StO}_{2}$ for all three $\mathrm{THI}$ levels. 
Since no standard exists for the in vivo THC, a homogeneous tissue phantom consisting of Intralipid (Fresenius Kabi Clayton L.P., Clayton, NC, USA) and blood was used to evaluate the correlation of the THI to THC. This correlation was studied from zero THC to the estimated upper limit of THC within a volume of muscle tissue, $0.2 \mathrm{mM}$ [14] or $1.3 \mathrm{~g} / \mathrm{dl}$. Twenty milliliters of whole bovine blood, with $17.1 \mathrm{~g} / \mathrm{dl} \mathrm{Hbt}$ and $10 \mathrm{units} / \mathrm{ml}$ heparin, was added in $1 \mathrm{ml}$ increments to a $500 \mathrm{ml}$ mixture of $0.4 \mathrm{wt} \%$ Intralipid, $0.9 \%$ sodium chloride, $70 \%$ deionized water and $30 \%$ deuterium oxide. Deuterium oxide was used to optically adjust the tissue phantom to be optically equivalent to a muscle water concentration of $70 \mathrm{wt} \%$ [15]. The optical sensor was immersed within the Intralipid-blood mixture equilibrated to $6.2 \%$ oxygen, $\mathrm{pH}$ of 7.4 and a temperature of $37^{\circ} \mathrm{C}$. The $\mathrm{StO}_{2}$ level of the mixture ranged from about 65 to $75 \%$. To evaluate the THI sensitivity to different tissue scattering properties that could change the optical path length and the correlation of the THI to THC, the homogeneous tissue phantom procedure was replicated with $0.8 \mathrm{wt} \%$ and 0.2 wt $\%$ Intralipid.

The estimated optical scattering coefficients at $800 \mathrm{~nm}$ for the $0.2 \mathrm{wt} \%, 0.4 \mathrm{wt} \%$ and $0.8 \mathrm{wt} \%$ Intralipid solutions, prior to adding blood, are $2 / \mathrm{cm}, 4 / \mathrm{cm}$, and $8 / \mathrm{cm}$, respectively [16]. Red blood cells contribute to the overall scattering coefficient and are estimated to contribute another $2 / \mathrm{cm}$ to the $800 \mathrm{~nm}$ scattering coefficient at $2 \%$ hematocrit or about $0.67 \mathrm{~g} / \mathrm{dl}$ [17]. An IL 682 Co-Oximeter (Instrumentation Laboratory, Lexington, MA, USA) was used to measure the Hbt of the whole blood added to the Intralipid solution.

\section{Human study volunteers: normal tissue hemoglobin index range}

This was a prospective, single-center, observational study in 434 nonhospitalized human volunteers who were employees of Hutchinson Technology Inc. All human studies were approved by the Western Institutional Review Board of Olympia, Washington. Males and females were enrolled who were 18 years and older, who had intact skin on the thenar eminence, and who gave written informed consent. There were no exclusion criteria.

Continuous thenar muscle $\mathrm{StO}_{2}$ and $\mathrm{THI}$ measurements were obtained from the right hand of resting subjects for 5 minutes. Heart rate and blood pressure were recorded before and after the $\mathrm{StO}_{2}$ and THI monitoring period. Collected demographic information included gender, age, ethnic group, smoking behavior, height, weight, and hand dominance.

Blood pressure and heart rate were measured in 271 study volunteers with a health station (Model 300; LifeClinic International, Rockville, MD, USA). During these measurements, study volunteers sat upright in the health station's chair with the measured arm resting on the station's arm rest and the elbow angled at 90 to $135^{\circ}$. In the remaining 163 individuals, blood pressure and heart rate were obtained with a different automatic blood pressure monitor (Model HEM-711ACN; Omron Healthcare Inc., Bannockburn, IL, USA). The subjects rested in a reclining chair with elbow angles of 135 to $180^{\circ}$. An interim analysis of the first 271 subjects revealed a thenar $\mathrm{StO}_{2}$ reference range lower than previously reported [18]. The previous study did not report the posture of their nonambulatory study subjects. After corresponding with an author of the previous study, we measured our remaining 163 study subjects in a reclined sitting posture to better replicate what was previously done [18].

\section{Human study volunteers: induced upper-extremity ischemia and exsanguination}

This was a prospective, single-center, observational study in 30 nonhospitalized human volunteers, all employed by Hutchinson Technology Inc. The sample population included an equal number of males and females aged 18 to 65 years who had intact skin on the thenar eminence, and who offered written consent. Exclusion criteria included history of limb injury or surgery, vascular disease, coagulopathy, or inability to ingest $325 \mathrm{mg}$ acetylsalicylic acid before starting the study.

Continuous thenar $\mathrm{StO}_{2}$ and $\mathrm{THI}$ measurements were obtained from both thenar sites of volunteers at rest on a gurney. Head-of-bed elevation was adjusted from $60^{\circ}$ to $30^{\circ}$ to $0^{\circ}$ with at least 5 minutes of rest between adjustments. An automated pneumatic tourniquet (A.T.S. 2000; Zimmer Inc., Warsaw, IN, USA) was placed around the upper arm and inflated to $200 \mathrm{mmHg}$ for 5 minutes. Upon releasing the cuff pressure for 5 minutes and observing $\mathrm{StO}_{2}$ recovery, the pneumatic tourniquet was inflated to $50 \mathrm{mmHg}$ to create venous blood flow occlusion for 5 minutes. After 5 minutes and $\mathrm{StO}_{2}$ recovery, the $\mathrm{StO}_{2}$ sensor was removed from the opposite hand to conduct the exsanguination procedure.

To accomplish exsanguination, the arm was supported in a vertical position for 1 minute. A $600 \mathrm{ml}$ intravenous bag, filled with $375 \mathrm{ml}$ water, was placed in the palm of the hand to evenly distribute the bandage pressure [19]. A 4 inch Esmarch bandage (Tetra Medical Supply Corp., Niles, IL, USA) was single wrapped with a one-half overlap from the finger tips to the upper forearm. The pneumatic cuff was then placed around the forearm, proximal to the elbow, and was inflated to $200 \mathrm{mmHg}$. After cuff inflation, the Esmarch bandage was removed and the $\mathrm{StO}_{2}$ sensor was reapplied to the thenar site. The elapsed time from application of the Esmarch bandage to cuff deflation did not exceed 6 minutes. The left and right hands of both male and female groups were alternately assigned to either the blood vessel occlusion or exsanguination procedures.

Previous research using a scintigraphic technique with injected radiolabeled erythrocytes has shown that a similar exsanguination procedure applied to the upper limb of 10 
healthy volunteers provides an average 69\% reduction in tissue blood volume [20]. For our study, the estimated nadir $\mathrm{THI}$ for $100 \%$ blood volume reduction $\left(\mathrm{THI}_{100}\right.$ ) was estimated from the nadir $\mathrm{THI}$ measured during exsanguination $\left(\mathrm{THI}_{69}\right)$, having an assumed 69\% volume reduction in blood. With THI prior to exsanguination $\left(\mathrm{THI}_{0}\right)$ measured, the following equation was used to calculate $\mathrm{THI}_{100}$ :

$$
\mathrm{THI}_{100}=\mathrm{THI}_{0}-\frac{\left(\mathrm{THI}_{0}-\mathrm{THI}_{69}\right)}{0.69}
$$

Heart rate and blood pressure were recorded before the $\mathrm{StO}_{2}$ and $\mathrm{THI}$ monitoring period. Collected demographic information included gender, age, ethnic group, height, weight, and hand dominance.

\section{Porcine hind limb: blood hemoglobin dilution}

The University of Minnesota Animal Use Committee, in accordance with established guidelines for the treatment of laboratory animals, approved this study of five male pigs weighing 18 to $28 \mathrm{~kg}$ each. Prior to anesthesia induction, a subcutaneous tissue depth $\leq 1.5 \mathrm{~mm}$ was verified with a skinfold caliper. Intramuscular ketamine $20 \mathrm{mg} / \mathrm{kg}$ and intravenous propofol 2 to $6 \mathrm{mg} / \mathrm{kg}$ were used to induce anesthesia. After intubation, anesthesia was maintained with $60 \%$ inhaled nitrous oxide and continued administration of propofol. One dose of intravenous heparin 100 units $/ \mathrm{kg}$ was given, administered after surgery.

An InSpectra ${ }^{\mathrm{TM}}$ optical sensor was applied to the mid medial thigh of both hind limbs. A pulmonary artery catheter was placed via the internal jugular vein and an arterial line was placed into the carotid artery. During laparotomy, a splenectomy was performed and the distal aorta and vena cava were surgically accessed to facilitate cross-clamping to create acute hind limb ischemia. The femoral artery and vein of the right hind limb were accessed and fitted with annular ultrasonic flow transducers (Model TS420; Transonic Systems, Inc., Ithaca, NY, USA).

The total blood hemoglobin concentration was lowered by removing blood from the pulmonary artery catheter and replenishing the shed blood with Hextend ${ }^{\circledR}$ (Hospira, Inc., Lake Forest, IL, USA) to achieve targeted systemic hemoglobin levels of $13 \mathrm{~g} / \mathrm{dl}, 10 \mathrm{~g} / \mathrm{dl}, 7 \mathrm{~g} / \mathrm{dl}$, and $4 \mathrm{~g} / \mathrm{dl}$. A $20 \mathrm{mg}$ bolus of furosemide was used to hemoconcentrate three of the five animals to elevate the baseline $\mathrm{Hbt}$ level to approximately $13 \mathrm{~g} / \mathrm{dl}$. To achieve $0.5 \mathrm{~g} / \mathrm{dl} \mathrm{Hbt}$ measured in the right femoral vein, the distal aorta was clamped and Hextend ${ }^{\circledR}$ was perfused below the cross-clamp site. The right femoral vein was incised to facilitate syringe sampling of the diluted blood effluent. After each targeted systemic Hbt level had been achieved, the $\mathrm{StO}_{2}, \mathrm{THI}$, cardiac output, femoral artery and venous blood flows, blood pressures, temperature, $\mathrm{pH}$, blood gases, oxygen saturation, lactate, hemoglobin, and base excess measurements were collected. $\mathrm{StO}_{2}$ and $\mathrm{THI}$ were subsequently measured during replicate aorta and vena cava 3-minute cross-clamp occlusions. $\mathrm{StO}_{2}$ and $\mathrm{THI}$ were recorded continuously.

\section{Statistical methods}

For the tissue phantom and porcine hind limb experiments, scatter plots and linear regression models were used to describe the relationships between the THI and the independent variables of $\mathrm{Hbt}$ and $\mathrm{StO}_{2}$. The squared Pearson correlation coefficient [21] was used to assess the degree of model fit. Squaring the correlation coefficient and multiplying it by 100 describes the percentage variability in observed $\mathrm{THI}$ attributable to changes in the independent variables.

For the human volunteer studies, mean and one standard deviation values were calculated for all measurement groups. The nonparametric Dunn's multiple-range test was used to evaluate differences between pairs of means for levels within a group. Correlation of $\mathrm{StO}_{2}$ and $\mathrm{THI}$ to numeric data, such as blood pressure, was performed with a Spearman rank twotailed test. All mean tests were evaluated at $95 \%$ confidence. The coefficient of variation (standard deviation/mean) was used to evaluate THI variability in human volunteers.

\section{Results \\ Isolated blood-tissue phantom: tissue hemoglobin index sensitivity to total hemoglobin}

The linear regression models of Figure 1 describing the THI as a function of $\mathrm{StO}_{2}$ were used to predict $\mathrm{THI}$ values at zero and $100 \% \mathrm{StO}_{2}$. This $\mathrm{THI}$ difference across the extreme $\mathrm{StO}_{2}$ range was then divided by the predicted $\mathrm{THI}$ at zero $\mathrm{StO}_{2}$ to obtain the percentage change in the $\mathrm{THI}$ reading for full-scale change in $\mathrm{StO}_{2}$. The resultant absolute crosstalk errors were $3.1 \%, 1.4 \%$, and $10.2 \%$ for $y$-intercept THI values of 5.8, 11.4, and 18.0, respectively. Figure 1 also shows that the $\mathrm{THI}$ signal has more random noise at the highest tested $\mathrm{THI}$ level and has the greatest crosstalk error with $\mathrm{StO}_{2}>90 \%$.

In Figure 2 the $\mathrm{THI}$ has a strong linear correlation $\left(r^{2}>0.99\right)$ to the hemoglobin concentration in a homogeneous suspension of Intralipid and red blood cells at three different scattering strength levels. A comparison of the linear equation slopes of Figure 2 reveals that a twofold increase in the optical scattering coefficient from 2 to $4 / \mathrm{cm}$ causes a $16 \%$ increase in THI. An increase in the scattering coefficient from 4 to $8 / \mathrm{cm}$ results in a $20 \%$ increase in THI. At $4 / \mathrm{cm}$ optical scattering, the sensitivity of $\mathrm{THI}$ to a change of $\pm 1 / \mathrm{cm}$ in optical scattering is estimated to be 5 to $8 \%$ of the $\mathrm{THI}$ reading.

\section{Human study volunteers: normal tissue hemoglobin index range}

Tables 1 and 2 summarize the variable and attribute demographic study measurements. For 434 volunteers, the THI mean and one standard deviation limit was $14.1 \pm 1.6$. The 
Figure 1

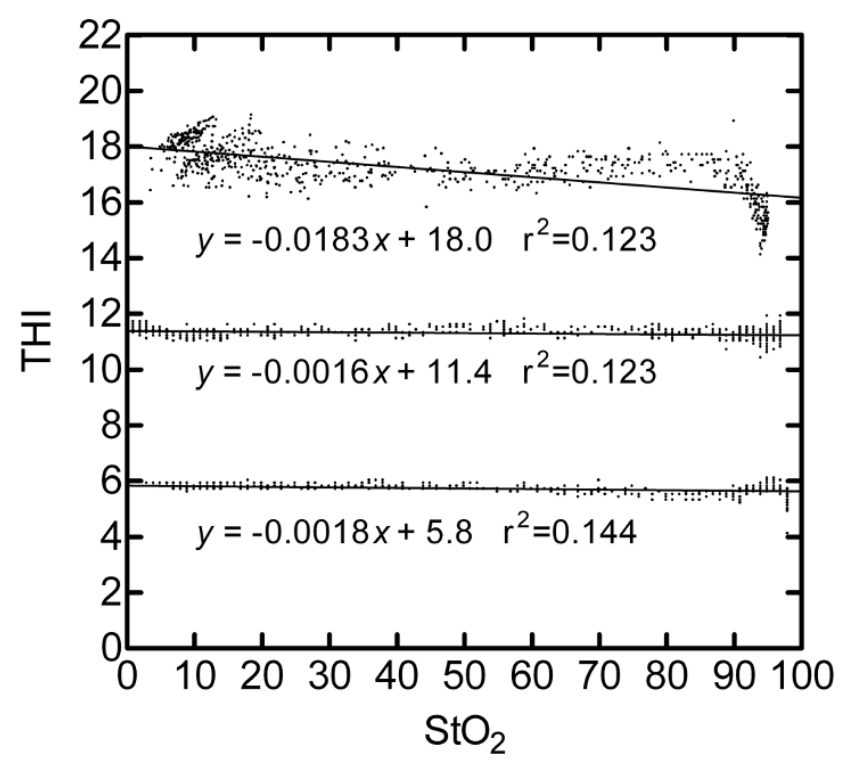

Tissue hemoglobin index at constant total hemoglobin absorption during variable hemoglobin oxygen saturation. The tissue hemoglobin index (THI) was measured at three constant total hemoglobin absorption conditions during variable hemoglobin oxygen saturation $\left(\mathrm{StO}_{2}\right)$ conditions. The nominal THI measurements near 6 and 12 were obtained from $6 \mathrm{~g} / \mathrm{dl}$ and $12 \mathrm{~g} / \mathrm{dl}$ bovine blood flowing through the dual-layer flow cell apparatus [11] at a blood thickness of $1.0 \mathrm{~mm}$. At $12 \mathrm{~g} / \mathrm{dl} \mathrm{Hbt}$ and $1.5 \mathrm{~mm}$ blood layer thickness, the nominal THI of 18 was obtained.

THI weakly correlated with $\mathrm{StO}_{2}$ (Spearman $r=0.243,95 \%$ confidence interval $=0.149$ to 0.332 ). The $\mathrm{TH}$ did not correlate with age, height, weight, body mass index, systolic blood pressure, diastolic blood pressure, mean arterial pressure, or heart rate. The coefficient of variation for THI $(11 \%)$ was less than that for blood pressure $(14 \%)$ and that for heart rate (16\%).

The THI was lower in smokers versus nonsmokers (14.0 vs. 14.7, respectively; $P<0.01)$ and in reclined posture versus upright posture ( 13.9 vs. 14.4 , respectively; $P<0.01$ ).

\section{Human study volunteers: induced upper-extremity ischemia and exsanguination}

Table 3 summarizes the $\mathrm{StO}_{2}$ and $\mathrm{TH}$ results for all subjects and includes the patient demographic and hemodynamic measurements. A multiple-level comparison test for all rows within each experimental condition of Table 3 indicated statistically different mean $\mathrm{StO}_{2}$ and $\mathrm{THI}$ differences $(P<0.05)$, except for the baseline and baseline recovery measurements for the arterial occlusion, venous occlusion, and blood volume exsanguination conditions. Gender influenced $\mathrm{StO}_{2}$ baseline resting measurements (females had average $\mathrm{StO}_{2}$ about 3 units lower than males) but had no statistically significant influence on THI. The measured hand,
Figure 2

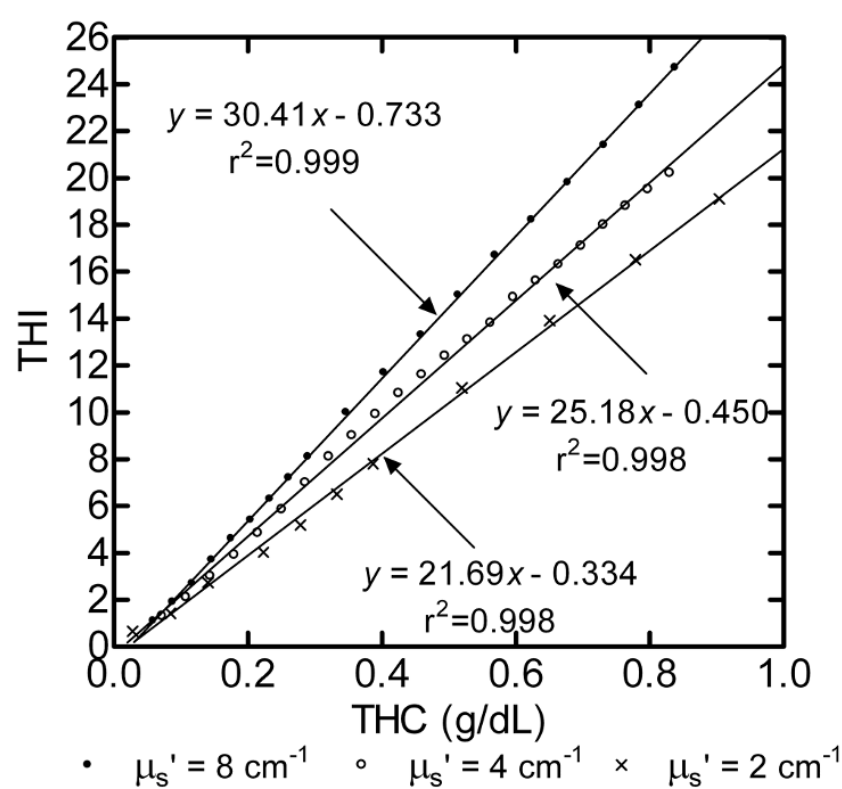

Tissue hemoglobin index at variable total hemoglobin concentration and optical scattering. Correlation of the tissue hemoglobin index (THI) to total tissue hemoglobin concentration (THC) within a homogenous mixture of bovine blood and Intralipid at three background optical scattering conditions, $0.2,0.4$ and $0.8 \mathrm{wt} \%$ Intralipid. Bovine blood having $17 \mathrm{~g} / \mathrm{dl}$ total hemoglobin concentration was stepwise added in $1 \mathrm{ml}$ increments to $500 \mathrm{ml}$ Intralipid solution having $0.9 \mathrm{wt} \% \mathrm{NaCl}, 30$ vol\% deuterium oxide, and deionized water. The mixture was pumped through a hollow flow cell apparatus [11] and was equilibrated to $6.2 \%$ oxygen, $5 \%$ carbon dioxide, $7.4 \mathrm{pH}$ and $37^{\circ} \mathrm{C}$. $\mu_{\mathrm{s}}{ }^{\prime}$, optical scattering coefficient.

left hand versus right hand, had no significant influence on the mean measurements ( $P>0.05$; results not shown).

The THI during arterial and venous occlusion exhibited different trends compared with the pre-occlusion THI. At the end of arterial occlusion the THI decreased $4.0 \pm 2.0$ units, while at the end of venous occlusion the THI increased $1.5 \pm 1.0$ units. Using Equation (2) with the individual THI values (not shown) measured at the $0^{\circ}$ head-of-bed elevation condition prior to ishcemia (THIO) and the nadir condition during Esmarch bandage exsanguination (THI69), the estimated THI for $100 \%$ blood volume exsanguination (residual THI) would be $3.7 \pm 2.0$ units.

\section{Porcine hind limb: blood hemoglobin dilution}

Figure 3 shows continuous hind limb THI measurements recorded during one experiment.

THI readings in five experiments weakly correlated to $\mathrm{Hbt}$ $\left(r^{2}=0.266\right)$, with Hbt ranging from 14 to $4 \mathrm{~g} / \mathrm{dll}$ (Figure 4a). For individual experiments, the THI to Hbt correlation was best in Experiment $4\left(\mathrm{THI}=0.317 \mathrm{Hbt}+6.16, r^{2}=0.996\right)$ and was worst in Experiment $1(\mathrm{THI}=0.08 \mathrm{Hbt}+8.39$, 
Table 1

Variable demographic data for the $\mathbf{4 3 4}$ human volunteers enrolled in the normal THI range study

\begin{tabular}{lcr} 
Characteristic & Mean \pm standard deviation & Coefficient of variation (\%) \\
\hline Age (years) & $42.3 \pm 10.72$ & 25 \\
Height $(\mathrm{cm})$ & $172.0 \pm 10.72$ & 6 \\
Weight $(\mathrm{kg})$ & $83.5 \pm 18.95$ & 23 \\
Body mass index $\left(\mathrm{kg} / \mathrm{m}^{2}\right)$ & $28 \pm 6.1$ & 22 \\
Systolic blood pressure $(\mathrm{mmHg})$ & $128 \pm 18.6$ & 15 \\
Diastolic blood pressure $(\mathrm{mmHg})$ & $80 \pm 11.5$ & 14 \\
Mean arterial pressure $(\mathrm{mmHg})$ & $96 \pm 13.0$ & 14 \\
Heart rate (beats/minute) & $70 \pm 11.2$ & 16 \\
Thenar eminence StO & \\
Thenar eminence $\mathrm{THI}$ & $81.4 \pm 5.25$ & 6
\end{tabular}

Coefficient of variation $=($ Mean/Standard deviation $) \times 100$. Variation in the tissue hemoglobin index (THI) among subjects was less than blood pressure and heart rate. $\mathrm{StO}_{2}$, tissue hemoglobin oxygen saturation.

Table 2

Attribute data for the $\mathbf{4 3 4}$ human volunteers enrolled in the tissue hemoglobin index range study

\begin{tabular}{|c|c|c|c|}
\hline Characteristic & Value & Tissue hemoglobin index & Tissue hemoglobin oxygen saturation (\%) \\
\hline Posture & & * & * \\
\hline Sitting reclined & 271 & $13.9 \pm 1.55$ & $83.3 \pm 4.01$ \\
\hline Sitting upright & 163 & $14.4 \pm 1.62$ & $78.3 \pm 5.57$ \\
\hline Gender & & & * \\
\hline Male & 235 & $14.1 \pm 1.58$ & $83.3 \pm 4.29$ \\
\hline Female & 199 & $14.1 \pm 1.63$ & $79.3 \pm 5.47$ \\
\hline Age (years) & $42.3 \pm 10.7$ & & \\
\hline \multicolumn{4}{|l|}{ Ethnicity } \\
\hline White & 410 & $14.1 \pm 1.62$ & $81.4 \pm 5.30$ \\
\hline Other & 11 & $13.5 \pm 0.82$ & $81.9 \pm 3.14$ \\
\hline Hispanic & 6 & $14.3 \pm 1.37$ & $85.1 \pm 6.19$ \\
\hline Indian & 6 & $12.9 \pm 1.02$ & $80.4 \pm 2.86$ \\
\hline Black & 1 & $12.4 \pm \mathrm{na}$ & $78.0 \pm$ na \\
\hline Smoker & & * & \\
\hline No & 392 & $14.7 \pm 1.39$ & $81.5 \pm 5.25$ \\
\hline Yes & 42 & $14.0 \pm 1.61$ & $81.3 \pm 5.35$ \\
\hline Hours last smoked & $4.4 \pm 5.1$ & & \\
\hline \multicolumn{4}{|l|}{ Dominant hand measured } \\
\hline Yes & 395 & $14.1 \pm 1.61$ & $81.4 \pm 5.35$ \\
\hline No & 39 & $13.9 \pm 1.47$ & $82.2 \pm 4.04$ \\
\hline
\end{tabular}

Data presented as number of subjects or mean \pm standard deviation. Posture and smoking habit influenced the tissue hemoglobin index. ${ }^{\star}$ Characteristic parameter had a statistically significant effect, $P<0.05$. na, not applicable. 
Table 3

THI and $\mathrm{StO}_{2}$ measurements in $\mathbf{3 0}$ healthy human volunteers before, during, and after acute ischemia

\begin{tabular}{|c|c|c|}
\hline Experimental condition & Tissue hemoglobin index & Tissue hemoglobin oxygen saturation \\
\hline Head-of-bed elevation (no ischemia) & ${ }^{*} 0^{\circ}, 60^{\circ}$ & ${ }^{*} 0^{\circ}, 30^{\circ}, 60^{\circ}$ \\
\hline $0^{\circ}$ & $14.6 \pm 1.68$ & $81.5 \pm 5.11$ \\
\hline $30^{\circ}$ & $15.0 \pm 1.60$ & $78.7 \pm 5.17$ \\
\hline $60^{\circ}$ & $15.2 \pm 1.66$ & $75.3 \pm 5.86$ \\
\hline Arterial cuff occlusion & ${ }^{*}$ All except baselines & ${ }^{*}$ All except baselines \\
\hline Baseline & $14.6 \pm 1.68$ & $82.0 \pm 5.33$ \\
\hline End & $10.6 \pm 1.81$ & $28.2 \pm 10.9$ \\
\hline Recovery peak & $18.7 \pm 2.71$ & $95.3 \pm 1.86$ \\
\hline Recovery baseline & $14.8 \pm 1.61$ & $82.1 \pm 4.57$ \\
\hline Venous cuff occlusion & ${ }^{*}$ All except baselines & ${ }^{*}$ All except baselines \\
\hline Baseline & $14.8 \pm 1.61$ & $82.1 \pm 4.45$ \\
\hline End & $16.2 \pm 1.53$ & $68.4 \pm 6.84$ \\
\hline Recovery baseline & $14.5 \pm 1.74$ & $79.6 \pm 4.90$ \\
\hline Esmarch bandage exsanguination & *All & *All \\
\hline Nadir & $7.0 \pm 1.56$ & $31.7 \pm 19.3$ \\
\hline Residual (calculated, Equation (2)) & $3.7 \pm 2.0$ & Not applicable \\
\hline Recovery peak & $16.2 \pm 2.49$ & $92.1 \pm 3.63$ \\
\hline Recovery baseline & $13.7 \pm 1.90$ & $78.1 \pm 6.58$ \\
\hline \multicolumn{3}{|l|}{ Demographic characteristics } \\
\hline Age (years) & $41.8 \pm 9.09$ & \\
\hline Height (inches) & $68.6 \pm 3.47$ & \\
\hline Weight (pounds) & $171 \pm 30.6$ & \\
\hline Body mass index $\left(\mathrm{kg} / \mathrm{m}^{2}\right)$ & $25.5 \pm 3.68$ & \\
\hline Systolic blood pressure $(\mathrm{mmHg})$ & $126 \pm 7.9$ & \\
\hline Diastolic blood pressure $(\mathrm{mmHg})$ & $78 \pm 8.0$ & \\
\hline Mean arterial pressure $(\mathrm{mmHg})$ & $94 \pm 7.4$ & \\
\hline Heart rate (beats/minute) & $67 \pm 11.6$ & \\
\hline
\end{tabular}

Data presented as mean \pm one standard deviation. Baseline measurements were obtained before inducing ischemia. All ischemia and ischemia recovery measurements were performed at $0^{\circ}$ bed elevation. The tissue hemoglobin index (THI) mean was manipulated from 7.0 to 18.7 under conditions of constant blood hemoglobin concentration. *Rows having statistically different means, $P<0.05$. StO ${ }_{2}$, tissue hemoglobin oxygen saturation.

$\left.r^{2}=0.929\right)$. After locally perfusing the hind limbs with a nonhemoglobin perfusate $\left(\right.$ Hextend $\left.^{\circledR}\right)$ and obtaining an effluent femoral vein blood hemoglobin concentration near $0.5 \mathrm{~g} / \mathrm{dl}$, there was a remaining (residual) $\mathrm{THI}$ of $2.8 \pm 0.6$ units.

With selective venous occlusion, the THI levels increased as shown in Figure 3. The magnitude of the $\mathrm{THI}$ increase with 3 minutes of venous occlusion $(\Delta \mathrm{THI})$ had a stronger association with the blood hemoglobin concentration $(\Delta \mathrm{THI}=$ $0.248 \mathrm{Hbt}+0.07, r^{2}=0.624$; Figure $4 \mathrm{~b}$ ) than the steady- state baseline $\mathrm{THI}$ value $\left(\mathrm{THI}=0.174 \mathrm{Hbt}+6.14, r^{2}=0.266\right.$; Figure 4a). Table 4 summarizes all hemodynamic measurements recorded for each steady-state hemoglobin condition. No hemodynamic information other than the $\mathrm{StO}_{2}, \mathrm{THI}$, and blood $\mathrm{Hbt}$ was measured during the $0.5 \mathrm{~g} / \mathrm{dl} \mathrm{Hbt}$ condition.

\section{Discussion}

Isolated blood-tissue phantom: tissue hemoglobin index sensitivity to total hemoglobin

The experiments using the tissue phantom model provide evidence that the THI metric is specific to (Figure 1) and 
Figure 3

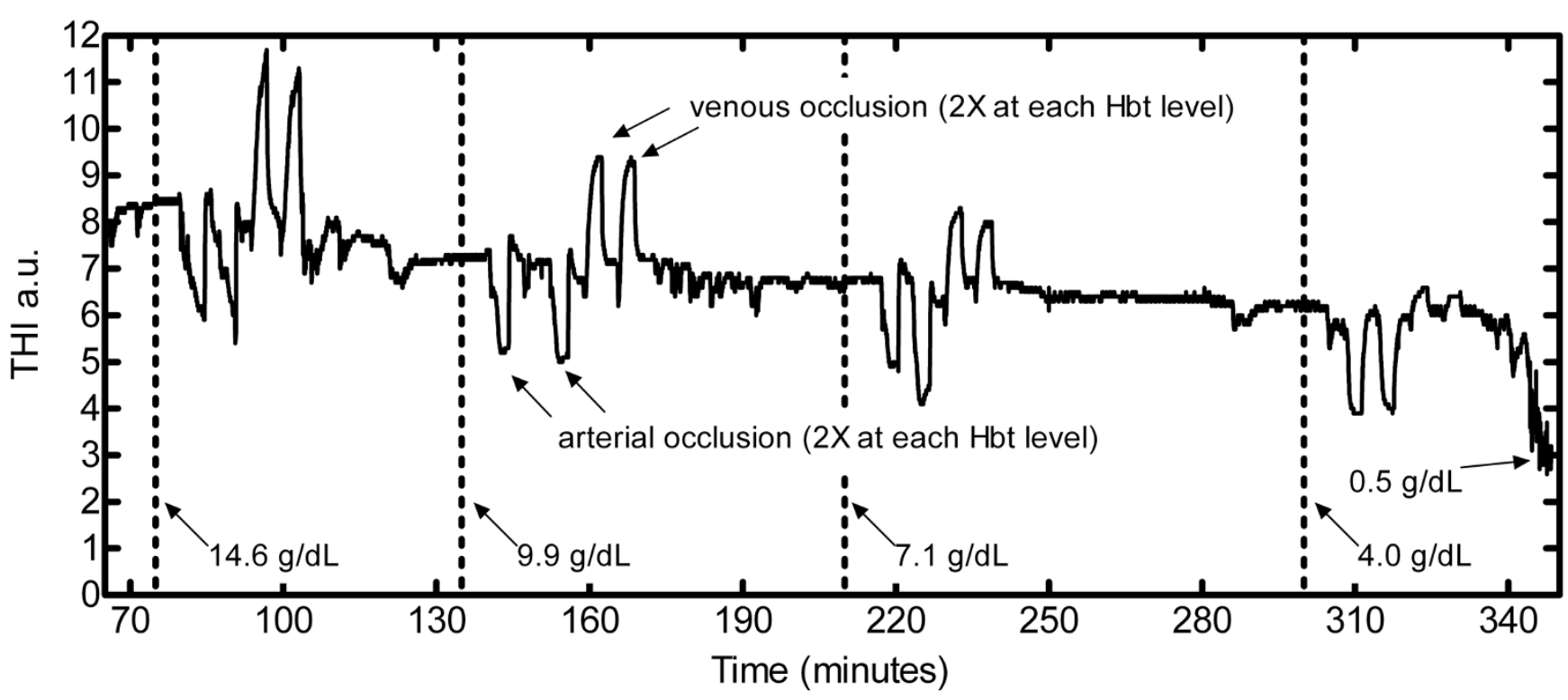

Porcine hind limb tissue hemoglobin index measurements during isovolumetrically diluted arterial blood hemoglobin concentration. The last hemoglobin concentration condition involved purfusing Hextend ${ }^{\circledR}$ directly into the distal abdominal aorta with a cross-clamp upstream of the pressurized infusion point. Effluent from the femoral vein was then sampled to measure the resultant localized hind limb hemoglobin concentration $(0.5 \mathrm{~g} / \mathrm{dl})$. a.u., arbitrary units; Hbt, total hemoglobin concentration.

Figure 4

(a)

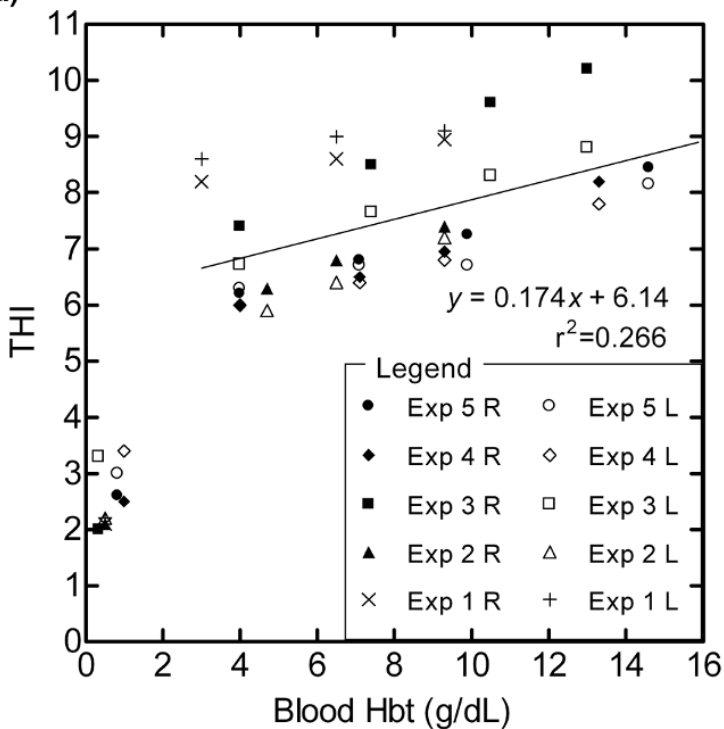

(b)

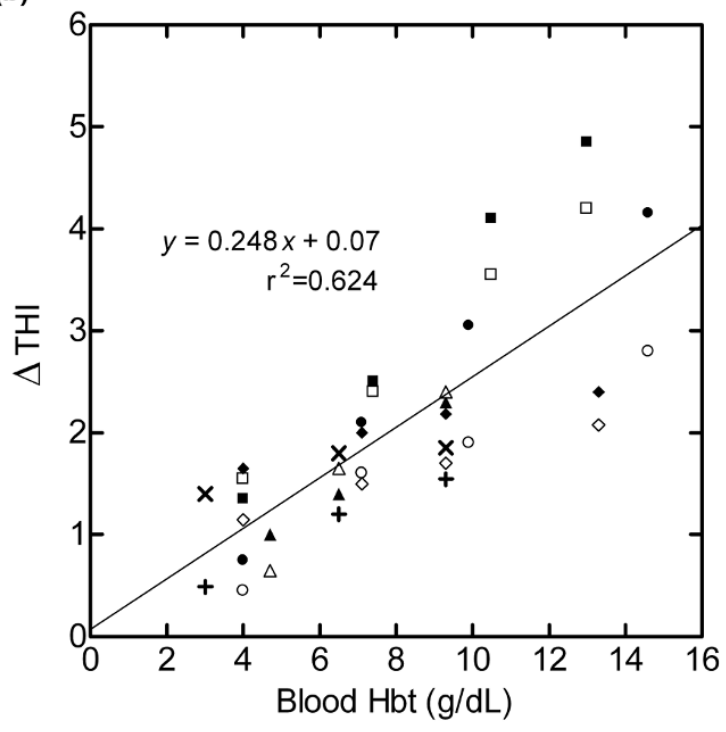

Correlation of tissue hemoglobin index to arterial blood hemoglobin concentration during isovolumetric hemodilution. As shown in the legend the (a) baseline THI values, and (b) change in THI during 3-minute venous occlusion ( $\Delta \mathrm{THI}$ ) are from five animal experiments (Exp 1 to Exp 5) in which both right $(\mathrm{R})$ and left $(\mathrm{L})$ hind limbs were simultaneously measured. The right limb had the femoral artery and vein surgically accessed to locate annular ring flow transducers, and generally had higher (a) THI (mean difference $0.32, P=0.05$ ) and (b) $\Delta$ THI (mean difference $0.44, P<0.05$ ). 
Table 4

\begin{tabular}{|c|c|c|c|c|}
\hline \multirow[b]{2}{*}{ Characteristic } & \multicolumn{4}{|c|}{ Total hemoglobin concentration } \\
\hline & $13 \mathrm{~g} / \mathrm{dl}$ & $10 \mathrm{~g} / \mathrm{dl}$ & $7 \mathrm{~g} / \mathrm{dl}$ & $4 \mathrm{~g} / \mathrm{dl}$ \\
\hline Number of measurements & 3 & 5 & 5 & 5 \\
\hline Arterial total hemoglobin $(\mathrm{g} / \mathrm{dl})^{\mathrm{a}}$ & 13.6 (13 to 14.6$)$ & 9.7 (9.3 to 10.5$)$ & $6.9(6.5$ to 7.4$)$ & 3.9 (3 to 4.7 ) \\
\hline Cardiac output $(\mathrm{ml} / \mathrm{min} / \mathrm{kg})$ & $110 \pm 47$ & $131 \pm 37$ & $160 \pm 77$ & $168 \pm 98$ \\
\hline Femoral artery flow $(\mathrm{ml} / \mathrm{min} / \mathrm{kg})$ & $4.8 \pm 1.6$ & $6.0 \pm 2.2$ & $5.9 \pm 1.9$ & $6.1 \pm 2.0$ \\
\hline Heart rate (beats/minute) & $97 \pm 9^{\star 4}$ & $113 \pm 16$ & $127 \pm 29$ & $155 \pm 39 * 13$ \\
\hline Systolic blood pressure $(\mathrm{mmHg})$ & $97 \pm 2$ & $99 \pm 10$ & $99 \pm 10$ & $91 \pm 22$ \\
\hline Diastolic blood pressure $(\mathrm{mmHg})$ & $69 \pm 4$ & $65 \pm 9$ & $69 \pm 13$ & $54 \pm 16$ \\
\hline Mixed $\mathrm{SmvO}_{2}(\%)$ & $83.0 \pm 4.4^{\star 4}$ & $73.8 \pm 5.5$ & $69.0 \pm 11.4$ & $61.2 \pm 19.3^{* 13}$ \\
\hline Hind limb $\mathrm{StO}_{2}(\%)$ & $89.0 \pm 2.8^{\star 10}$ and 7 & $80.0 \pm 6.3^{* 13}$ & $82.7 \pm 5.6^{* 13}$ & $84.1 \pm 6.2$ \\
\hline Hind limb THI (arbitrary) & $8.3 \pm 1.1^{\star 4}$ & $7.8 \pm 1.2$ & $7.3 \pm 1.0$ & $6.8 \pm 1.0^{\star 13}$ \\
\hline
\end{tabular}

Data presented as mean \pm standard deviation. aMean and range shown since the variable was controlled to have no overlap in values. A nonparametric Dunn's multiple comparison test was used to study differences in mean values. ${ }^{\star} P<0.05$ for the hemoglobin column(s) indicated. The tissue hemoglobin index was statistically different only when total hemoglobin concentration changed from 13 to $4 \mathrm{~g} / \mathrm{dl}$. SmvO $\mathrm{m}_{2}$, mixed venous hemoglobin oxygen saturation; $\mathrm{StO}_{2}$, tissue hemoglobin oxygen saturation.

sensitive to (Figure 2) the total amount of hemoglobin for a given optical path length or volume that the detected light signal interrogates. The dual-layer phantom results of Figure 1 show that, at a fixed blood layer thickness, the THI signal doubled - changing from 5.8 to 11.4 - when $\mathrm{Hbt}$ was doubled from 6 to $12 \mathrm{~g} / \mathrm{dl}$. At constant $\mathrm{Hbt}(12 \mathrm{~g} / \mathrm{dl})$, an increase in the THI from 11.4 to 18.0 was similarly proportional to the increase in blood layer thickness (from 1.0 to $1.5 \mathrm{~mm}$ ). These results suggest that both vascular $\mathrm{Hbt}$ and vascular density or thickness (diameter) would influence THI readings in vivo.

The results of Figure 2 show that the optical scattering properties of tissue can also influence a $\mathrm{THI}$ reading. As the optical scattering coefficient increases, the mean distance between scattering events (1/Optical scattering coefficient) increases and therefore the increased traversed distance of detected light (optical path length) results in more total hemoglobin absorption events and thus a greater THI value. The four-factor range in background optical scattering was chosen to estimate the sensitivity of THI to a change in tissue optical scattering. The resultant $<10 \% \mathrm{THI}$ reading change per $1 / \mathrm{cm}$ scattering coefficient change provides a basis for studying how THI might change in vivo using tissue optical scattering properties reported in the published literature.

The reported absolute value for tissue optical scattering measured in vivo on human limbs varies widely, from about 4 to $10 / \mathrm{cm}$, and appears specific to a measured tissue bed, to the reporting research institution, or to the measurement equipment used [22-24]. Information regarding optical scattering changes for forearm tissue within a fixed NIRS measurement device suggests that optical scattering changes, observed in intersubject variability studies $[22,23,25]$ or ischemia studies [26], does not exceed a factor of two. Although the authors have found no report of optical scattering variation in the thenar eminence tissue bed, the variability in this bed may be less than that in forearm since subcutaneous tissue thickness either from fat or edema is reported to be less variable at the thenar site [27]. The in vivo THI error from an extreme change in optical scattering (twofold change) therefore appears to be less than $20 \%$ of the $\mathrm{THI}$ reading.

\section{Human study volunteers: normal tissue hemoglobin index range}

The present study is the first investigation and report of the THI range in a nonhospitalized large group of human volunteers. The THI mean (14.1) and standard deviation (1.6) values are similar to the reference range for blood hemoglobin concentration (13.5 to $15.1 \mathrm{~g} / \mathrm{dl}$ ) [28]. This closeness of normal THI to normal Hbt reflects how the THI was calibrated against $\mathrm{Hbt}$ in a phantom tissue model mimicking the optical attenuation of tissue with normal levels of hemoglobin when measured with a $15 \mathrm{~mm}$ optical probe spacing. Different optical probe spacings and tissue locations can yield significantly different results. For instance, the author's stomach, which has about 1 inch of adipose thickness, measured a THI of 5 units compared with near 14 units on the thenar when using a $15 \mathrm{~mm}$ optical probe spacing distance. Adipose tissue has less dense vasculature than muscle and is estimated to have one-third of the THC of 
muscle (0.05 mM vs. $0.15 \mathrm{mM}$, respectively) [29]. A $25 \mathrm{~mm}$ optical spacing on the thenar can produce a normal THI value near 22 units [6] since the $25 \mathrm{~mm}$ probe, compared with a $15 \mathrm{~mm}$ probe, results in a significantly larger optical path length. The PSF of Equation (1) would need to be utilized to allow different optical probe spacings to have a common THI scale.

Our previous research identified that the mean THI from 10 healthy volunteer subjects and 10 sepsis patients closely resembled the mean $\mathrm{Hbt}$ measurements in both groups [5]. The correlation of $\mathrm{THI}$ to $\mathrm{Hbt}$ for individually paired measurements within the sepsis patient cohort, however, had only weak linear correlation to $\mathrm{Hbt}\left(r^{2}=0.14\right)$ [30], similar to the results of the porcine hind limb hemodilution study.

Variation in optical scattering properties of the thenar eminence tissue between the 434 measurement subjects is unknown. The observed coefficient of variation for the THI, equal to $11 \%$, is less than the calculated coefficients of variation for other hemodynamic variables of this study (15\% for systolic blood pressure and 16\% for heart rate) (Table 1). The relatively low coefficient of variation for normal THI indicates that optical scattering variation does not significantly confound THI measurements. We have seen THI values near 4 units in hospitalized sepsis patients [30], which indicates that the THI in patients can be well outside the normal reference range in nonhospitalized study subjects (14.1 \pm 1.6 units). More investigation is needed to determine whether an abnormally low $\mathrm{THI}$ reading is diagnostically useful or relevant to a patient's health status or treatment.

\section{Human study volunteers: induced upper-extremity ischemia and exsanguination}

A total of $\mathbf{3 0}$ human subjects underwent acute arm ischemia conditions evoked by arterial occlusion, venous occlusion, and blood volume exsanguination. Head-of-bed elevation, used clinically to mitigate ventilator-associated pneumonia and elevated intracranial pressure [31,32], was evaluated for its effect on $\mathrm{THI}$ and $\mathrm{StO}_{2}$ variability. The main findings of the present study are that the $\mathrm{THI}$ trend during cuff-induced ischemia differentiated arterial and venous blood flow occlusions, and that the residual THI signal when extrapolated to $100 \%$ blood volume exsanguination was $3.7 \pm 2.0$ THI units. Since the blood hemoglobin concentration would be fairly constant during the study measurements, the results indicate that regional ischemia and posture could confound any correlation between the $\mathrm{THI}$ and $\mathrm{Hbt}$.

Venous occlusion with a pneumatic cuff initially stops venous blood flow until the venous pressure increases above the occlusion pressure. A reduced venous flow resumes once the venous pressure rises above the cuff pressure [33]. This could explain why $\mathrm{StO}_{2}$ during venous occlusion had limited change (an approximately $14 \mathrm{StO}_{2}$ unit decrease) compared with arterial occlusion (an approximately $54 \quad \mathrm{StO}_{2}$ unit decrease). While $\mathrm{StO}_{2}$ decreased during both venous and arterial occlusion, the $\mathrm{THI}$ increased $1.5 \pm 1.0$ units with venous occlusion and decreased $4.0 \pm 2.0$ units with arterial occlusion. These results suggest that the $\mathrm{THI}$ trend during ischemia might help to identify whether a flow resistance or blockage is emanating from the venous or arterial vascular compartment, similar to other studies measuring NIRSderived relative THC changes in muscle free flaps [34]. The porcine hind limb THI readings always increased during distal vena cava cross-clamp occlusion (Figures 3 and 4b), while aorta cross-clamping caused the THI to always drop as indicated in Figure 3. While a rise in the THI during venous occlusion is expected because of venous pooling and blood volume congestion, decreases in the THI during arterial occlusion may have been caused by blood volume reduction. Other NIRS researchers have noted a decrease in total hemoglobin NIRS signals during arterial occlusion [35-37]. In compliant blood vessels, a decrease in arterial vascular pressure would reduce the vascular volume and hence cause the THC and THI to decrease.

The posture of the limb and the influence of gravity might also affect blood drainage and movement out of the measured vascular space. The head-of-bed elevation results of Table 3 show that $\mathrm{StO}_{2}$ decreased on average 6 units with $60^{\circ}$ of elevation while the average THI slightly increased 0.6 units. The sitting upright and reclined results in Table 2 also show that the average $\mathrm{StO}_{2}$ was 5 units lower while the average THI was 0.5 units higher with an upright posture. These results confirm that limb posture can have a measurable influence on $\mathrm{StO}_{2}$ and $\mathrm{THI}$ measurements. With the arm positioned below heart level, the hand's venous pressure and venous blood volume would increase. The lower oxygen saturated venous blood could then become a larger fraction of the total blood volume that $\mathrm{StO}_{2}$ is measuring, and thus lower the $\mathrm{StO}_{2}$.

Other researchers have used scintillation X-ray measures to demonstrate that Esmarch bandage exsanguination of the lower forearm causes a $69 \%$ reduction in tissue blood volume [38]. We assume that the similar exsanguination technique of our study produces a similar $69 \%$ reduction in tissue blood volume. The nadir THI during the exsanguination procedure was $7.0 \pm 1.6$ units. Extrapolation to $100 \%$ blood volume reduction from a baseline THI value of 14.6 (Equation (2)) results in an estimated residual THI value of $3.7 \pm 2.0$ units. This residual value may indicate that the maximum potential contribution of myoglobin to the THI signals is approximately $\leq 25 \%$ of the baseline THI values in healthy volunteers. The $3.7 \pm 2.0$ nadir $\mathrm{THI}$ value in the present study compared with the $2.8 \pm 0.6$ residual THI value determined in the porcine hind limb study can possibly be explained by the higher concentration of myoglobin reported in human muscle compared with porcine muscle $(4.7 \mathrm{mg} / \mathrm{g}$ and $<1 \mathrm{mg} / \mathrm{g}$ wet weight, respectively) $[39,40]$. The nonzero venous Hbt level $(0.5 \mathrm{~g} / \mathrm{dl})$ would elevate the residual $\mathrm{THI}$ in 
the porcine study and cause an overestimation of the myoglobin contribution. Deviations from the $69 \%$ blood volume exsanguination assumption for the human limb exsanguination experiments would change the estimated myoglobin contribution to human thenar THI measurements.

Since the average THI value in 434 human thenar tissue sites $(14.1 \pm 1.6)$ was greater than the average $\mathrm{THI}$ value in five porcine hind limbs $(8.3 \pm 1.1)$, the potential contribution of myoglobin to the human thenar $\mathrm{THI}$ is lower. However, it is evident that the contribution of myoglobin to a THI signal potentially changes for any given level of THI. For instance, in human thenar tissue with a normal THI value of 14.1 , the myoglobin contribution may be limited to $25 \%$; but at a $\mathrm{THI}$ level of 5 , the myoglobin contribution might approach $75 \%$. A THI measurement can therefore help to identify the tissue compartment, cellular versus vascular, where $\mathrm{StO}_{2}$ is predominantly measured. It is not clear whether myoglobin and $\mathrm{StO}_{2}$ change concomitantly or independently in resting muscle [41]. Our previous work involving measurement of $\mathrm{StO}_{2}$ in oxygen consumption-inhibited porcine organs having myoglobin (heart and hind limb) and not having myoglobin (kidney) suggested that myoglobin did not significantly influence $\mathrm{StO}_{2}$ specificity to hemoglobin oxygen saturation measured from arterial and venous blood samples [11]. Regardless of myoglobin's contribution to NIRS signals, a low $\mathrm{StO}_{2}$ resulting from either myoglobin or hemoglobin desaturation would indicate a lower oxygen reserve available to the tissue.

\section{Porcine hind limb: blood hemoglobin dilution}

The isovolumetric hemodilution experiments indicate that the $\mathrm{THI}$ is not a direct measure of $\mathrm{Hbt}$, although $\mathrm{THI}$ trends might indicate a changing $\mathrm{Hbt}$. Whereas tissue phantom experiments indicated a strong linear correlation $\left(r^{2}>0.99\right.$; Figure 2) of the THI to total hemoglobin changes, the in vivo correlation of the $\mathrm{THI}$ to $\mathrm{Hbt}$ was nonlinear from 14 to near $0 \mathrm{~g} / \mathrm{dl}$ and was only weakly linear $\left(r^{2}=0.26\right.$; Figure $\left.4 \mathrm{a}\right)$ within the physiologic relevant range, from 4 to $16 \mathrm{~g} / \mathrm{dl}$.

NIRS optical signals originate primarily from the arteriolar, capillary, and venule microvascular compartments [42]. The relative amount of blood in each of these compartments determines where an attenuated or absorbed optical signal is being measured. In resting muscle tissue, one-third to onehalf of the capillaries are open and perfused with blood [43]. Vascular tone reduction (vasodilation) and a resultant capillary recruitment from higher capillary pressure could explain why $\mathrm{THC}$, and hence the THI, might be preserved even though dramatic changes in blood hemoglobin concentration occur. The general increase in cardiac output and femoral artery blood flow (Table 4) during Hbt dilution would result from microvascular arteriole vasodilation and additional blood flow to newly opened capillaries. In human volunteer subjects in whom the blood $\mathrm{Hbt}$ was reduced to $5.0 \mathrm{~g} / \mathrm{dl}$, researchers have observed decreased systemic vascular resistance and increased cardiac index [44]. A reduction in blood viscosity from hemodilution would decrease flow resistance and would also contribute to the observed increase in the systemic and local blood flows [45].

Myoglobin could be a significant factor contributing to the lack of correlation between the $\mathrm{THI}$ and $\mathrm{Hbt}$ as well as between $\mathrm{StO}_{2}$ and mixed venous hemoglobin oxygen saturation (Table 4) since hemoglobin and myoglobin have similar absorption characteristics in the near-infrared wavelength region $(650$ to $900 \mathrm{~nm})$ [46]. The estimated contribution of myoglobin to NIRS-derived hemoglobin signals is unclear. Reports have ranged from suggesting that nearly all of the NIRS-derived signal is from myoglobin [47] to suggesting $90 \%$ of the signal is coming from hemoglobin $[42,48]$. Other studies have suggested that the myoglobin contribution is linked to the blood hemoglobin concentration since the constant concentration of tissue myoglobin becomes a larger fraction of the NIRS signal as the hemoglobin signal is diluted [49]. The results of our porcine study suggest that the THI may be useful in interpreting the potential contribution of myoglobin to NIRS-derived signals such as $\mathrm{StO}_{2}$. The residual $\mathrm{THI}$ of $2.8 \pm 0.6$ units, observed when the femoral vein hemoglobin concentration was $0.5 \mathrm{~g} / \mathrm{dl}$, suggests that the average myoglobin signal was no more than $40 \%$ of the average $\mathrm{THI}$ value (equal to $6.8 \pm 1.0$ ) when blood $\mathrm{Hbt}$ was near $4 \mathrm{~g} / \mathrm{dl}$, and was no more than $34 \%$ of the average $\mathrm{THI}$ value (equal to $8.3 \pm 1.0$ ) with blood $\mathrm{Hbt}$ near $13 \mathrm{~g} / \mathrm{dl}$. Other researchers have found in isolated porcine hearts that the myoglobin contribution may range from 63 to $46 \%$, with one-half $(5.1 \pm 0.4 \mathrm{~g} / \mathrm{dl} \mathrm{Hbt})$ and whole blood perfusate mixtures, respectively [49].

Venous cuff occlusion techniques have been used to isolate NIRS signals to the nonpulsating venous blood compartment $[50,51]$. The increased venous pressure causes venous pooling and a subsequent increase in THI. In Figure 4 the right limbs have slightly higher $\mathrm{THI}$, and $\Delta \mathrm{THI}$ could be from venous obstruction from the flow transducer applied to the right hind limb femoral vein. The magnitude of the THI increase following a 3-minute period of $50 \mathrm{mmHg}$ venous occlusion pressure produced a differential $\mathrm{THI}$ signal $(\Delta \mathrm{THI})$ that had a significantly better correlation to Hbt compared with steady-state THI measurements. The $y$ intercept of 0.07 in Figure $4 \mathrm{~b}$ indicates that any offset from myoglobin absorption is potentially removed and a stronger linear relationship to $\mathrm{Hbt}$ is obtained ( $r^{2}=0.62$ vs. $r^{2}=0.26$; Figure 4). Further studies may be warranted to examine whether the THI combined with venous occlusion techniques can be optimized to produce a reliable continuous non-invasive measurement indicative of $\mathrm{Hbt}$ status.

After surgical preparation and before beginning the porcine hemodilution experiments, it was observed that the starting hind limb THI was approximately one-half of the average THI value (14.1 \pm 1.6 units) measured on the thenar eminence of 
human subjects. Postoperative porcine Hbt levels were low, about $10 \mathrm{~g} / \mathrm{dl}$, possibly stemming from the age of the pigs and from the fluids given during the surgical phase of the experiment. A $20 \mathrm{mg}$ bolus of furosemide diuretic was used to hemoconcentrate three of the five animals to boost the starting hemoglobin level. At $13.6 \pm 0.9 \mathrm{~g} / \mathrm{dl} \mathrm{Hbt}$, the average hind limb THI value of $8.3 \pm 1.1$ units was still much lower than that observed in humans. Differences in tissue blood volume, resulting from differences in vascular density or myoglobin concentration between the human thenar and porcine hind limb, could account for the significantly different observed baseline THI values. The results of the human blood exsanguination experiments (see the exsanguination discussion section), however, indicate that myoglobin differences between human and porcine muscle may be less relevant to this THI difference. Differences in the optical scattering properties of porcine hind limb and human thenar eminence could also be a contributing factor for the lower observed THI baseline in the porcine hind limb. The subcutaneous tissue thickness of the hind limbs, more similar to that in the thenar eminence (about $\leq 1.5 \mathrm{~mm}$ ), would make optical scattering differences less likely to have caused the THI differences.

\section{Conclusions}

Steady-state THI values do not reliably indicate the blood hemoglobin concentration. Regional ischemia and posture can significantly affect $\mathrm{THI}$ readings under conditions where the blood hemoglobin concentration is constant. The contribution of myoglobin to the $\mathrm{THI}$ and $\mathrm{StO}_{2}$ is dependent upon the THI magnitude. At a $\mathrm{THI}$ of 4 , nearly all of the $\mathrm{THI}$ and $\mathrm{StO}_{2}$ signal measured on thenar eminence is from myoglobin. At normal $\mathrm{THI}(>10)$, the $\mathrm{THI}$ and $\mathrm{StO}_{2}$ signals are mostly from THC.

\section{Competing interests}

$\mathrm{DM}$ is an employee of the company that manufactures the InSpectra ${ }^{\mathrm{TM}}$ device evaluated in the present study. DM owns stock in the company and is listed as an inventor on patents related to the content of this manuscript.

\section{Acknowledgement}

Funding for the present study was provided by Hutchinson Technology Inc., Hutchinson, Minnesota, USA.

This article is part of Critical Care Volume 13 Supplement 5: Tissue oxygenation $\left(\mathrm{StO}_{2}\right)$ in healthy volunteers and critically-ill patients. The full contents of the supplement are available online at http://ccforum. com/supplements/13/S5. Publication of the supplement has been supported with funding from Hutchinson Technology Inc.

\section{References}

1. McKinley BA, Marvin RG, Cocanour CS, Moore FA: Tissue hemoglobin $\mathrm{O}_{2}$ saturation during resuscitation of traumatic shock monitored using near infrared spectrometry. J Trauma 2000, 48:637-642.

2. Cohn SM, Nathens AB, Moore FA, Rhee P, Puyana JC, Moore EE, Beilman GJ: Tissue oxygen saturation predicts the development of organ dysfunction during traumatic shock resuscitation. J Trauma 2007, 62:44-54; discussion 54-55.

3. Pareznik R, Knezevic R, Voga G, Podbregar M: Changes in muscle tissue oxygenation during stagnant ischemia in septic patients. Intensive Care Med 2006, 32:87-92.

4. Creteur J, Carollo T, Soldati G, Buchele G, De Backer D, Vincent JL: The prognostic value of muscle $\mathrm{StO}_{2}$ in septic patients. Intensive Care Med 2007, 33:1549-1556.

5. Skarda DE, Mulier KE, Myers DE, Taylor JH, Beilman GJ: Dynamic near-infrared spectroscopy measurements in patients with severe sepsis. Shock 2007, 27:348-353.

6. Doerschug KC, Delsing AS, Schmidt GA, Haynes WG: Impairments in microvascular reactivity are related to organ failure in human sepsis. Am J Physiol Heart Circ Physiol 2007, 293: $\mathrm{H} 1065-\mathrm{H} 1071$.

7. Dani C, Pezzati M, Martelli E, Prussi C, Bertini G, Rubaltelli FF: Effect of blood transfusions on cerebral haemodynamics in preterm infants. Acta Paediatr 2002, 91:938-941.

8. Torella F, Cowley R, Thorniley MS, McCollum CN: Monitoring blood loss with near infrared spectroscopy. Comp Biochem Physiol A Mol Integr Physiol 2002, 132:199-203.

9. Rendell M, Anderson E, Schlueter W, Mailliard J, Honigs D, Rosenthal R: Determination of hemoglobin levels in the finger using near infrared spectroscopy. Clin Lab Haematol 2003, 25: 93-97.

10. Cerussi A, Van Woerkom R, Waffarn F, Tromberg B: Noninvasive monitoring of red blood cell transfusion in very low birthweight infants using diffuse optical spectroscopy. J Biomed Opt 2005, 10:051401.

11. Myers DE, Anderson LD, Seifert RP, Ortner JP, Cooper CE, Beilman GJ, Mowlem JD: Noninvasive method for measuring local hemoglobin oxygen saturation in tissue using wide gap second derivative near-infrared spectroscopy. J Biomed Opt 2005, 10:034017.

12. Cooper CE, Elwell CE, Meek JH, Matcher SJ, Wyatt JS, Cope M, Delpy DT: The noninvasive measurement of absolute cerebral deoxyhemoglobin concentration and mean optical path length in the neonatal brain by second derivative near infrared spectroscopy. Pediatr Res 1996, 39:32-38.

13. Cui W, Kumar C, Chance B: Expermental study of migration depth for the photons measured at sample surface. Proc SPIE 1991, 1431:180-191.

14. Binzoni T, Quaresima V, Barattelli G, Hiltbrand E, Gurke L, Terrier $F$, Cerretelli $P$, Ferrari M: Energy metabolism and interstitial fluid displacement in human gastrocnemius during short ischemic cycles. J Appl Physiol 1998, 85:1244-1251.

15. Matcher SJ, Cope M, Delpy DT: Use of the water absorption spectrum to quantify tissue chromophore concentration changes in near-infrared spectroscopy. Phys Med Biol 1994, 39:177-196.

16. van Staveren HJ, Moes CJM, van Marle J, Prahl SA, van Gemert MJC: Light scattering in Intralipid-10\% in the wavelength range of 400-100 nm. Appl Opt 1991, 30:4507-4514.

17. Lovell AT, Hebden JC, Goldstone JC, Cope M: Determination of the transport scattering coefficient of red blood cells. Proc SPIE 1999, 3597:175-182.

18. Crookes BA, Cohn SM, Bloch S, Amortegui J, Manning R, Li P, Proctor MS, Hallal A, Blackbourne LH, Benjamin R, Soffer D, Habib F, Schulman Cl, Duncan R, Proctor KG: Can near-infrared spectroscopy identify the severity of shock in trauma patients? J Trauma 2005, 58:806-813; discussion 813-816.

19. Harris PC, Scott S, Evans RA: Hand exsanguination: prospective randomised blind study of an established versus a modified technique. J Hand Surg Br 2002, 27:361-362.

20. Blond L, Madsen JL: Exsanguination of the upper $\operatorname{limb}$ in healthy young volunteers. J Bone Joint Surg Br 2002, 84:489491.

21. Weisberg S: Simple linear regression. In Applied Linear Regression. 2nd edition. New York: John Wiley and Sons; 1985: $1-32$.

22. Franceschini MA, Gratton E, Hueber D, Fantini S: Near-infrared absorption and scattering spectra of tissues in vivo. Proc SPIE 1999, 3597:526-531.

23. Matcher SJ, Kirkpatrick P, Nahid K, Cope M, Delpy DT: Absolute quantification methods in tissue near infrared spectroscopy. Proc SPIE 1995, 2389:486-495.

24. Cheong S, Prahl SA, Welch AJ: A review of the optical properties of biological tissues. IEEE J Quantum Electron 1990, 256: 2166-2185.

25. Duncan A, Meek JH, Clemence M, Elwell CE, Tyszczuk L, Cope $\mathrm{M}$, Delpy DT: Optical pathlength measurements on adult head, 
calf and forearm and the head of the newborn infant using phase resolved optical spectroscopy. Phys Med Biol 1995, 40: 295-304.

26. Ferrari M, Wei Q, Carraresi L, De Blasi RA, Zaccanti G: Time resolved spectroscopy of the human forearm. J Photochem Photobiol B 16:141-158.

27. Poeze M: Tissue-oxygenation assessment using near-infrared spectroscopy during severe sepsis: confounding effects of tissue edema on $\mathrm{StO}_{2}$ values. Intensive Care Med 2006, 32: 788-789.

28. Bauer JD: Hemoglobin. In Clinical Chemistry: Theory, Analysis, and Correlation. 2nd edition. St Louis, MO: CV Mosby Company; 1989:515-523.

29. Duck FA: Physical Properties of Tissues: A Comprehensive Reference Book. San Diego, CA: Academic Press; 1990:320-321.

30. Mulier KE, Skarda DE, Taylor JH, Myers DE, McGraw MK, Gallea BL, Beilman GJ: Near-infrared spectroscopy in patients with severe sepsis: correlations with invasive hemodynamic measurements. Surg Infect 2008, 9:515-519.

31. Keeley L: Reducing the risk of ventilator-acquired pneumonia through head of bed elevation. Nurs Crit Care 2007, 12:287294.

32. Blissitt PA, Mitchell PH, Newell DW, Woods SL, Belza B: Cerebrovascular dynamics with head-of-bed elevation in patients with mild or moderate vasospasm after aneurysmal subarachnoid hemorrhage. Am J Crit Care 2006, 15:206-216.

33. Levick JR: Hemodynamics: flow, pressure and resistance. In An Introduction to Cardiovascular Physiology. 4th edition. London: Arnold Publishers; 2003:104-130.

34. Repez A, Oroszy D, Arnez ZM: Continuous postoperative monitoring of cutaneous free flaps using near infrared spectroscopy. J Plast Reconstr Aesthet Surg 2008, 61:71-77.

35. Irwin MS, Thorniley MS, Dore CJ, Green CJ: Near infra-red spectroscopy: a non-invasive monitor of perfusion and oxygenation within the microcirculation of limbs and flaps. Br J Plast Surg 1995, 48:14-22.

36. Hampson NB, Piantadosi CA: Near infrared monitoring of human skeletal muscle oxygenation during forearm ischemia. $J$ Appl Physiol 1988, 64:2449-2457.

37. Hosokawa T, Kobayashi R, Araki T, Sakamoto T, Fuchigami K, Kaku N, Kakegawa T: Clinical evaluation of severe ischemic limbs by tissue reflection spectrophotometry. Kurume Med J 1994, 41:187-191.

38. Blond L, Madsen JL: Exsanguination of the upper limb in healthy young volunteers. J Bone Joint Surg Br 2002, 84:489491.

39. Newcom DW, Stalder KJ, Baas TJ, Goodwin RN, Parrish FC Wiegand BR: Breed differences and genetic parameters of myoglobin concentration in porcine longissimus muscle. Anim Sci 2004, 82:2264-2268.

40. Moller P, Sylven C: Myoglobin in human skeletal muscle. Scand J Clin Lab Invest 1981, 41:479-482.

41. Ward KR, Ivatury RR, Barbee RW, Terner J, Pittman R, Filho IP Spiess B: Near infrared spectroscopy for evaluation of the trauma patient: a technology review. Resuscitation 2006, 68: 27-44.

42. Mancini DM, Bolinger L, Li H, Kendrick K, Chance B, Wilson JR: Validation of near-infrared spectroscopy in humans. J Appl Physiol 1994, 77:2740-2747.

43. Levick JR: Specialization in individual circulations. In An Introduction to Cardiovascular Physiology. 4th edition. London: Arnold Publishers; 2003:251-277.

44. Gutierrez G, Reines HD, Wulf-Gutierrez ME: Clinical review: hemorrhagic shock. Crit Care 2004, 8:373-381.

45. Levick JR: Hemodynamics: flow, pressure and resistance. In An Introduction to Cardiovascular Physiology. 4th edition. London: Arnold Publishers; 2003:120-123.

46. Schenkman KA, Marble DR, Burns DH, Feigl EO: Optical spectroscopic method for in vivo measurement of cardiac myoglobin oxygen saturation. App/ Spectrosc 1999, 53:332-338.

47. Tran TK, Sailasuta N, Kreutzer U, Hurd R, Chung Y, Mole P, Kuno $\mathrm{S}$, Jue T: Comparative analysis of NMR and NIRS measurements of intracellular $\mathrm{PO}_{2}$ in human skeletal muscle. $\mathrm{Am} J$ Physiol 1999, 276(6 Pt 2):R1682-R1690.

48. Boushel R, Piantadosi CA: Near-infrared spectroscopy for monitoring muscle oxygenation. Acta Physiol Scand 2000, 168:615-622.
49. Nighswander-Rempel SP, Kupriyanov VV, Shaw RA: Relative contributions of hemoglobin and myoglobin to near-infrared spectroscopic images of cardiac tissue. App/ Spectrosc 2005, 59:190-193.

50. Yoxall CW, Weindling AM: Measurement of venous oxyhaemoglobin saturation in the adult human forearm by near infrared spectroscopy with venous occlusion. Med Biol Eng Comput 1997, 35:331-336.

51. De Blasi RA, Ferrari M, Natali A, Conti G, Mega A, Gasparetto A: Noninvasive measurement of forearm blood flow and oxygen consumption by near-infrared spectroscopy. J Appl Physiol 1994, 76:1388-1393. 